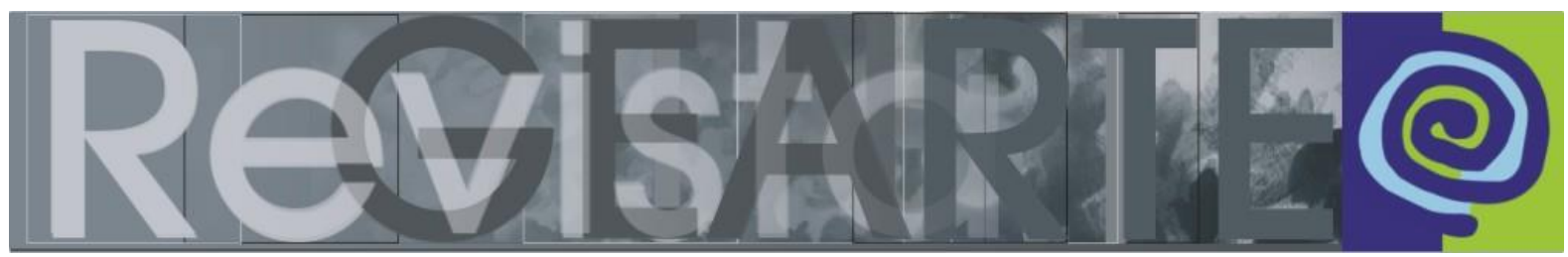

e-ISSN 2357-9854

\title{
Livros didáticos para o ensino da arte: não peça a eles o que eles não podem te dar
}

\author{
Consuelo Alcioni Borba Duarte Schlichta (Universidade Federal \\ do Paraná — UFPR, Curitiba/PR, Brasil) \\ Guilherme Gabriel Ballande Romanelli (Universidade Federal \\ do Paraná — UFPR, Curitiba/PR, Brasil) \\ Mauren Teuber (Universidade Estadual do Paraná - \\ UNESPAR, Curitiba/ PR, Brasil)
}

\begin{abstract}
RESUMO - Livros didáticos para o ensino da arte: não peça a eles o que eles não podem te dar - Este texto traz resultados de pesquisa realizada sobre a disciplina Arte e o lugar do livro didático na reorganização dos conteúdos sob a concepção de transdisciplinaridade entre diversos campos do saber, um dos critérios avaliativos propostos no Edital PNLD 2017. Analisa-se duas coleções de Arte aprovadas no PNLD 2017, partindo das críticas à polivalência e a valorização da transdisciplinaridade. Busca-se pensar a transdisciplinaridade diferentemente da polivalência dos anos de 1970, levando em conta o modelo para o qual o professor é formado? O livro didático joga na manutenção ou na extinção da prática de um único professor trabalhar as quatro linguagens? A formação proposta na licenciatura incorpora a proposição de um ensino da História da Arte em eixos temáticos? Por fim, aborda-se a imprecisão ou desconhecimento do objeto de estudo da Arte e das especificidades das linguagens, chamando os professores à participação nas proposições e decisões sobre os destinos da educação em Arte.
\end{abstract}

PALAVRAS-CHAVE

Livro didático. Ensino de Arte. Polivalência. Transdisciplinaridade. História(s) da(s) Arte(s).

ABSTRACT - Textbooks for art education: do not ask them what they can not give you - This text brings results of research carried out on the discipline Art and the place of the text book in the reorganization of the contents under the conception of transdisciplinarity among several fields of knowledge, one of the evaluation criteria proposed in the Edital PNLD 2017. It is analyzed two approved art textbooks collections in the PNLD 2017 starting from the critics to the polyvalence and the valorization of the transdisciplinarity. In order to think, does transdisciplinarity, unlike the polyvalence of the 1970s, consider the model for which the teacher is formed? Does the textbook play in maintaining or extinguishing the practice of a single art teacher working the four languages? Does the training proposed in the degree incorporate the proposition of a teaching of Art History, in thematic axes? Finally, we approach the imprecision or ignorance of the object of art study and the specificities of languages, calling teachers to participate in propositions and decisions about the destinies of education in art.

KEY WORDS

Textbook. Art education. Multifunctionality. Transdisciplinarity. History (ies) of Art (s). 


\section{Considerações iniciais}

A pesquisa aqui apresentada é resultado de uma investigação interinstitucional ${ }^{1}$ que tem como objeto de estudo o livro didático. Alguns de seus participantes investigam particularmente o livro didático para o ensino da Arte, no caso, duas coleções de livros didáticos públicos selecionados pelo Programa Nacional do Livro Didático (PNLD), distribuídos gratuitamente às escolas públicas do Ensino Fundamental II (de 6ำ a $9^{\circ}$ anos), mediante processo de escolha dos professores de Arte.

Pretende-se, pois, expor os pressupostos teóricos e metodológicos presentes nas duas coleções de livros didáticos de Arte aprovados na edição do PNLD 2017, o que permitirá por em evidência entre outros aspectos as concepções de Arte e de ensino.

A princípio, cabe situar o Programa Nacional do Livro Didático (PNLD), enquanto uma das políticas públicas do governo brasileiro ligado ao Ministério da Educação, que distribui gratuitamente livros didáticos às escolas públicas brasileiras, mediante seleção pública por uma comissão especialista e pela escolha de professores e equipes pedagógicas das escolas beneficiadas.

É muito recente a presença de livros didáticos para o componente curricular Arte no PNLD. Iniciou-se no PNLD 2015, quando foram distribuídos livros de Arte para o Ensino Médio; no seguinte, no PNLD 2016, para os anos iniciais do Ensino Fundamental, e no PNLD 2017, os anos finais do Ensino Fundamental recebem seus primeiros livros de Arte.

1 O grupo de pesquisa colaborativo, voltado ao estudo do livro didático em Arte, e, em articulação com o Núcleo de Pesquisas em Publicações Didáticas (NPPD-UFPR), envolve três instituições: duas universidades (a Universidade do Estado do Paraná, UNESPAR, por meio do seu Campus Curitiba II, FAP; e a Universidade Federal do Paraná, UFPR), e o Núcleo Regional de Educação de Ponta Grossa (NRE Ponta Grossa) jurisdicionado à Secretaria de Estado da Educação do Estado do Paraná, SEED/PR. 
O PNLD 2017 é trienal e prevê a utilização de livros para 2017, 2018 e $2019 .^{2}$ Para a disciplina de Arte, na edição de 2017, foram contempladas duas coleções de livros didáticos de natureza reutilizável, acompanhados de CD em áudio: Por toda parte, com distribuição de 6.112.637 exemplares da coleção, e Projeto Mosaico Arte, 4.547.073. Cada coleção é composta por quatro livros, um volume para cada ano, do 6ำ ao 9ano, com um total aproximado de 10 milhões de livros distribuídos para a disciplina de Arte.

Seguindo as estruturas curriculares previstas pela legislação educacional brasileira, os livros contemplam as quatro linguagens artísticas em um mesmo livro (Artes Visuais, Dança, Música e Teatro), refletindo o caráter polivalente da disciplina de Arte, que é geralmente ministrada por um único professor, na maioria dos casos, formado em uma das linguagens artísticas. Essa política acaba também pressionando as equipes pedagógicas e ou direção das escolas, que jogam para o professor a responsabilidade pelo ensino das demais linguagens, mesmo que isso se traduza na simplificação e inadequação dos conhecimentos artísticos apresentados aos alunos.

\section{Da polivalência à transdisciplinaridade: o que mudou?}

Ainda que não se pretenda esmiuçar os sentidos que impregnam os termos polivalência e interdisciplinaridade, ambos são palavras-chave para se compreender o papel destinado ao ensino da Arte, o primeiro, no contexto da Lei de Diretrizes e Bases (LDB) № 5.692, promulgada em 1971; o segundo, conforme desdobramentos da Lei de Diretrizes e Bases da Educação Nacional (LDB), no 9.394, de 1996, que trata da legislação vigente para a educação no contexto atual.

Também são citadas pelos autores das duas coleções: a interdisciplinaridade, a multidisciplinaridade, assim como novas tendências teórico-metodológicas: a

2 Dados atualizados em 2017: Nessa edição, atendendo o Ensino Fundamental, Campo e Ensino Médio, foram contempladas 117.690 escolas, 29.416.511 estudantes, distribuindo um total de 152.351.763 exemplares de livros e envolvendo um investimento total aproximado de $\mathrm{R} \$ 1.300 .000 .000,00$. Especificamente para $\mathrm{O}$ Ensino Fundamental anos finais, foram contempladas 49.702 escolas, beneficiados 10.238 .539 alunos, distribuídos um total de 79.216.538 exemplares de livros e com um investimento total de $R \$ 639.501 .256,49$. Dados disponíveis em: <http://www.fnde.gov.br/programas/programas-do-livro/livro-didatico/dados-estatisticos $>$. Acessado em: 10/03/2018. 
interculturalidade, o multiculturalismo, a estética do cotidiano, a cultura visual, com destaque para a Abordagem Triangular, de Ana Mae Barbosa (2002), assimilada por inúmeros professores de Arte, desde os anos de 1990.

Não se pode negar que a LDB 5692/71 foi um avanço, pois estabelece a Educação Artística como área obrigatória no currículo escolar para o ensino de 1e e $2^{\circ}$ graus. Porém, na prática, a pretensão de habilitar um aluno para atuar no ensino das quatro linguagens abrigadas sob a denominação Educação Artística, inviabilizouse desde o início (SCHLICHTA; SILVA, 2016). Ainda assim, na contramão das críticas encontra-se também justificativas em relação à prática polivalente, a exemplo da Resolução no 23, de 1973, do Conselho Federal de Educação.

\begin{abstract}
O professor do ensino de $1^{\circ}$ grau não tem que ser um especialista em determinadas divisões de arte. Conquanto, sem desconhecer essas divisões, cabe-lhe apresentar globalmente os recursos artísticos de expressão e comunicação, dentre os quais venham os estudantes a selecionar os que mais se ajustem às variáveis do seu mundo interior. O processo, no caso, é incomparavelmente mais importante que os resultados estéticos a obter.
\end{abstract}

Esse tipo de argumento é duplamente negativo: de um lado, desacredita a necessidade de especialização do professor; de outro, embora considere importante o conhecimento dessas divisões e dos recursos artísticos de comunicação e expressão, como fundamentais aos alunos, reduz o conhecimento da Arte a um receituário de técnicas. De qualquer modo, contraditoriamente, as críticas acabaram imputando à técnica a culpa por todos os males que assolam a educação em Arte, desconsiderando a origem da técnica: a noção de ofício, da Antiguidade, e a concepção de Arte como fazer, uma das definições mais conhecidas e recorrentes. Mas, não só, segundo Luigi Pareyson (1984), a Arte é também concebida como um conhecer e como um exprimir. Por isso, o simples fazer não basta para definir a Arte, enquanto trabalho criador.

A arte é também invenção. Ela não é execução de qualquer coisa já ideiada, realização de um projeto, produção segundo regras dadas ou predispostas. Ela é um tal fazer que, enquanto faz, inventa o por fazer e o modo de fazer (PAREYSON, 1984, p. 32, grifos do autor).

Certamente são muitas as implicações do desconhecimento de que execução e invenção constituem os dois lados do trabalho criador. A primeira, talvez, de reduzi- 
la à experiência pessoal com recursos artísticos de expressão e comunicação, seja lá o que se entenda por isso, regulada pela ideia de criatividade como dom natural.

Aliás, a visão de que a Arte é regida pelo mistério seguiu reproduzindo-se em preconceitos que ainda exercem influência, por exemplo, que o artista é alguém à parte da sociedade, um "marginal, excêntrico, e distante das condições usuais das pessoas comuns, por virtude do dom do gênio artístico" (WOLFF, 1982, p. 24). O que não se explica, conforme Wolff (1982, p. 23-24), é que essa visão particular do artista como marginal, alçada a universal, descende da visão romântica de artista do século XIX, e que a "ascensão do individualismo, concomitante com o desenvolvimento do capitalismo industrial" foi crucial para sua disseminação. Deduz-se daí que uma análise histórica do modelo de sociedade vigente é fundamental para esclarecer o que mudou desde a entrada da polivalência no ensino da Arte, à época da Educação Artística, até a transdisciplinaridade, no contexto atual de acirrados debates sobre as bases teóricas e metodológicas norteadoras do currículo nacional. Por fim, como o livro didático incorpora essas problemáticas.

Do ponto de vista histórico, a concepção de Arte como fazer cai como luva no projeto de fortalecimento do sistema capitalista, via LDB 5692/71, por conseguinte, da proposta de educação voltada à instrumentalização e habilitação dos trabalhadores para o mercado de trabalho. O ensino da Arte, nesse contexto, tende ao aprendizado de técnicas, fundado no "aprender a fazer", conforme pedagogia tecnicista (SAVIANI, 2010, p. 383).

De modo geral, as críticas ao ensino da Arte centrado nas técnicas, pós 1980, acabaram por fecundar compreensões diversas: a afirmação da Arte como trabalho criador, fundamentada na compreensão de que a oposição entre Arte e trabalho só "é válida quando o trabalho adota a forma de trabalho alienado" (VÁZQUEZ, 1978, p. 70); a entrada da concepção de Arte como conhecimento, que se revigora nas décadas pós 1980, e que tem sua versão mais acabada nos Parâmetros Curriculares Nacionais, particularmente no documento que trata sobre o ensino da Arte (1997).

No caso do livro didático, em particular nas décadas de 1980 e 1990, muitos autores, fundamentados na concepção de Arte como práxis criadora, realçam o SCHLICHTA, Consuelo Duarte; ROMANELLI, Guilherme Ballande; TEUBER, Mauren. 316 Livros didáticos para o ensino da arte: não peça a eles o que eles não podem te dar. Revista GEARTE, Porto Alegre, v. 5, n. 2, p. 312-325, maio/ago. 2018.

Disponível em: http://seer.ufrgs.br/gearte 
estudo dos procedimentos e instrumentos artísticos, a pesquisa de materiais e suportes, o exercício com as técnicas, conforme Vázquez (1977), que faz a crítica à técnica como práxis reiterativa ou fazer sem reflexão, e Pareyson (1984), que afirma: na Arte inventa-se o quê fazer e o como fazer. Enfim, advogam o acesso aos conhecimentos artísticos, fundamentais aos homens e mulheres na apropriação da realidade humana e social, via a Arte. Assim, respondia-se um duplo desafio: possibilitar ao aluno o domínio das técnicas e a compreensão de que o fazer do artista, se também invenção, não permanece na reprodução de regras já dadas.

Esse grupo, fundamentado em Vázquez (1977, p. 279), acentuava alguns traços que caracterizam a práxis criadora: "unidade entre o interior e o exterior, entre o subjetivo e o objetivo, no processo prático, imprevisibilidade do processo e de seu resultado", entre outros. Cabe observar que o desconhecimento dos traços que distinguem a práxis criadora da reiterativa traz sérias consequências tanto para a formação quanto para a atuação do professor, entre elas: a aceitação sem questionamento da interpretação da Arte como um fazer diferente e superior as outras formas de trabalho de modo a conduzir a Arte na escola, como uma atividade oposta ao trabalho; à hipertrofia da subjetividade no processo do artista (e do aluno) esquecendo-se que subjetividade e objetividade são os dois lados de um mesmo processo, no qual o artista (o aluno também) não é passivo, a produção não é um processo inerte assim como o resultado final não reflete o projeto ideal. Finalmente, cumpre observar que chegar a técnica é tarefa do artista, nesse caso o singular é importante, mas, no caso do ensino da Arte cumpre oportunizar ao aluno um amplo e profundo conhecimento sobre a produção artística, incluindo-se aí o exercício e o conhecimento das técnicas, o plural aqui é importante.

A pesquisa, nesse sentido, desnudou certos termos, muitas vezes, aceitos ou rechaçados sem questionamentos ou esclarecimento sobre seus fundamentos e que muitos deles afetam o ensino da Arte e a formação dos seus profissionais, a começar pela absorção e implementação das técnicas nos moldes do tecnicismo e da polivalência, levando muitos professores, sob condições historicamente adversas, a fazer malabarismos para dar conta do processo ensino aprendizagem de quatro linguagens. 
Feitas essas considerações, cabe problematizar: será que as críticas a polivalência fizeram efeito? No caso das coleções investigadas, em que a transdisciplinaridade é apresentada como organizadora dos conteúdos, abordados por meio de temas norteadores que perpassam as diferentes áreas de conhecimento (MEIRA, 2015, p. 170), leva-se em conta o modelo para o qual o professor é formado? Que avanços se propõem? O livro didático em Arte joga na manutenção ou na extinção da prática de um único professor trabalhar as quatro linguagens?

\section{Fragmentos de um mosaico: do ensino da História da Arte temática ao objeto do ensino da Arte}

É possível notar nos livros didáticos analisados uma mudança na organização dos conteúdos e métodos da História da Arte ensinada. Passa-se de uma História da Arte tratada apenas por grandes fatos ocorridos no passado, à custa de conteúdos informativos sobre o quê, quem, onde e quando, apresentados de forma linear, para uma abordagem de seus diferentes ritmos, espaços e tempos.

Nos moldes do ensino da História da Arte, até bem pouco tempo, vigorava uma dimensão cronológica e linear dos acontecimentos; usualmente realizada a partir da identificação e descrição de obras de Arte, com ênfase nos elementos formais e de composição; a apresentação de uma História da Arte seguindo um processo evolutivo, sequencial e homogêneo em consonância com o eixo espaço-temporal eurocêntrico; ou ainda uma História da Arte como história dos artistas, compositores, bailarinos e dramaturgos, privilegiando-se fragmentos da biografia e obra deslocados de contextos mais amplos. É comum a apresentação de dados biográficos, muitas vezes, na forma de uma listagem de referências bibliográficas no final do livro do professor, elaborada a partir de outros compêndios, dicionários, livros técnicos ou manuais. É o caso das coleções pesquisadas que se valem de autores como Fayga Ostrower, Ingrid Koudela, Viola Spolin, Antônio Costella, por exemplo.

Por outro lado, as mudanças nos métodos de ensinar História da Arte observada nos livros didáticos hoje refletem os questionamentos da disciplina de História, redefinições e reformas curriculares que atingem os conhecimentos escolares, a partir do processo de redemocratização dos anos de 1980, indicando os

SCHLICHTA, Consuelo Duarte; ROMANELLI, Guilherme Ballande; TEUBER, Mauren. 318

Livros didáticos para o ensino da arte: não peça a eles o que eles não podem te dar.

Revista GEARTE, Porto Alegre, v. 5, n. 2, p. 312-325, maio/ago. 2018.

Disponível em: http://seer.ufrgs.br/gearte 
consensos e discordâncias da área de ensino de História no que se refere à necessidade de renovação.

Fonseca (2003), ao tratar sobre o ensino da História, salienta que a História Tradicional, conhecida como positivismo histórico, dominou o século XIX, passando a ser discutida, questionada e transformada ao longo do século $\mathrm{XX}$, e que daí tem origem e se desenvolveu, a partir do movimento dos Annales, a "Nova História", incrementa o debate entre as diversas tendências teórico historiográficas e influencia as propostas curriculares. O PCN História (BRASIL, 1998) considera algumas possibilidades à renovação da história ensinada: 1) o favorecimento do conhecimento de diversas sociedades historicamente constituídas, por meio de estudos que considerem múltiplas temporalidades; 2) ruptura com a ordenação temporal dos conteúdos, distanciando-se da concepção positivista de linearidade e progressividade histórica; 3) e consenso sobre a impossibilidade de se estudar toda a história da humanidade em todos os tempos, partindo-se do pressuposto de que seu aprendizado pode ocorrer a partir do estudo de qualquer período histórico; 4) a organização da abordagem dos conteúdos em temas ou eixos temáticos, com base em preocupações do presente.

Assim é possível afirmar que a História temática emerge como alternativa para o ensino de História, ancorada inclusive pelas proposições dos PCN - Área de História (BRASIL, 1998), que contemplam a organização dos conteúdos por eixos temáticos. Entretanto, nessa pesquisa, não se localizou estudos anteriores que demarcassem na produção acadêmica, debates que avaliassem a incorporação dessa perspectiva no ensino da História da Arte na disciplina de Arte.

Obviamente, a Arte é uma disciplina nova entre as disciplinas escolares do Brasil e, segundo Rossi (2014, p. 91), talvez seja a que tem a mais peculiar trajetória de inserção na educação formal, pois é "apenas na década de 70 que aconteceu a inclusão obrigatória no currículo escolar; porém como mera atividade, não como disciplina, como as demais".

No caso da disciplina Arte, levando-se em conta a longa tradição do ensino da História, a ideia de se colocar lado a lado artistas que pertencem ao passado e ao SCHLICHTA, Consuelo Duarte; ROMANELLI, Guilherme Ballande; TEUBER, Mauren. 319 Livros didáticos para o ensino da arte: não peça a eles o que eles não podem te dar. Revista GEARTE, Porto Alegre, v. 5, n. 2, p. 312-325, maio/ago. 2018. 
presente, requer do professor aprofundamento das premissas teóricas e metodológicas que sustentam as orientações para o trabalho com tais propostas. $\mathrm{Na}$ coleção Projeto Mosaico, por exemplo, os autores referenciam inicialmente os temas interdisciplinares de cada um dos quatro livros: o corpo, a cidade, o planeta e a ancestralidade, problemas claramente contemporâneos. Contudo, as diretivas metodológicas, ainda iniciais, evidenciam que a contribuição do livro didático - na sistematização dos conteúdos e sua organização teórica e metodológica em temáticas que articulam diferentes campos do saber - quase sempre limita-se à introdução da dimensão social e cultural no estudo do artista, do período ou do movimento em questão.

Seus autores propõem, ano a ano, no caso da coleção Projeto Mosaico Arte, como linha predominante, a abordagem de um tema e uma linguagem: "O livro do corpo explora a dança, o livro da cidade trata das artes visuais e audiovisuais, o livro do planeta conecta-se com a música e o livro da ancestralidade mergulha no teatro" (MEIRA, 2015, p. 3). Explicam que a transdisciplinaridade se dá no âmbito da articulação entre um tema geral que perpassara os seis capítulos (e dois projetos) do livro e entre linguagens, conforme destacadas. As justificativas de articulação, sobretudo de corpo - dança e ancestralidade - teatro, de fato, comprovam a preocupação dos autores em conectar tema e conteúdos da linguagem: obras de Arte de épocas diferentes, que têm em comum um assunto, um modo de representação, figuração ou composição, uma problemática social, etc. Obviamente, as razões para tal articulação são claras, pois o corpo está para a dança assim como a ancestralidade (os rituais) está para o teatro.

Nesse ponto, é oportuno destacar um dos valores da coleção Por toda parte: jogar luz sobre o objeto de estudo da Arte. Evidentemente o domínio do conhecimento artístico é indispensável ao professor, caso contrário ele pouco extrairá das orientações pedagógicas, a exemplo da explicação de que "o som (intencional) é o centro para o qual tudo converge". Ora, os autores não estão aqui tratando do objeto de estudo da Música? É o que se depreende destes argumentos: 
conhecesse essas combinações para reproduzi-las de novo. Outro fator importante no decorrer dos tempos foi que essas composições podiam ser recriadas e novamente reproduzidas cada vez mais facilmente. É por essa razão que conhecemos muitas músicas, antigas e recentes. Algumas conservam sua elaboração original e outras foram modificadas mas chegaram até nós porque foram feitos registros de algum modo, dependendo dos recursos de cada época, e reproduzidas também diante do que estava disponível em relação a instrumentos e soluções de gravação. (UTUARI, 2015, p. 51).

De fato, é fundamental uma base material, extraída dos recursos de cada época, instrumentos e soluções de gravação, etc. Contudo - nossa discordância - a criação no campo da Música não ocorre porque "um dia" alguém começou "a criar composições, arranjos de sons". Entende-se que o processo de criação é muito mais complexo, pois, além de condições espirituais, implica também condições materiais e não se realiza assim, de repente ou sem mais nem menos. Seria acreditar que a criação artística é questão de inspiração, boa vontade, talento, independentemente dos recursos de cada época, instrumentos e soluções de gravação, como os próprios autores destacam.

Depois, sobre o objeto da Dança, pode-se deduzir que dão ênfase ao "movimento expressivo", e nas Artes Visuais, à imagem, mas também à Cultura Visual, pouco esclarecendo os professores sobre esses dois campos teórico-metodológicos, que desde os anos finais de 1980 travam um permanente embate. No Teatro, os autores dão destaque para o jogo, como objeto, e a improvisação teatral, como caminho metodológico, ainda que não o digam isso com todas as letras (UTUARI, 2015).

Considerando a imprecisão (em muitos casos o desconhecimento) do objeto de estudo da Arte, assim como das especificidades de cada linguagem: Artes Visuais, Dança, Música e Teatro, um dos critérios de nossa análise das coleções passou pela tentativa de extrair dos livros: qual o objeto de conhecimento do ensino da Arte, conforme os autores das duas coleções? Eles abordam um objeto de estudo específico para cada linguagem? Nas orientações pedagógicas gerais ou especificas pode-se apreender os fundamentos do objeto de conhecimento que se quer ensinar? 
Não é o caso, portanto, de criticar apenas, mas de reconhecer que o livro didático é um tema ausente na formação inicial de professores de Arte, basta lembrar a pouca tradição que o livro tem na disciplina. Além disso, apenas na última década, desde 2009, o PNLD completou a distribuição gratuita de livros nas escolas públicas, para os componentes tradicionais curriculares, e somente em 2015, a Arte passou a fazer parte do programa. Destaca-se, por fim, que muitos estudantes de licenciatura, na última década, "formaram-se professores sem ter passado pela experiência de ter os livros como material didáticos ou recurso para o ensino e aprendizagem, seja exercendo uma função de suporte dos conteúdos, apoio às atividades ou guia das aulas" (BRAGA, 2013, p. 85). E não é diferente para estudantes de licenciatura em cursos de Artes Visuais, Dança, Teatro ou Música.

\section{Considerações Finais}

Ao concluir, nossa posição primeira é a de louvar a conquista do componente curricular Arte pelo PNLD, uma conquista recente e que exige amadurecimento para se alcançar novos patamares de qualidade, no que tange às finalidades do ensino da Arte, como ocorreu em outras áreas do conhecimento que já gozam de uma tradição mais antiga, a exemplo da História e da Física. Reitera-se que essa é a primeira edição de livros didáticos públicos para os anos finais do Ensino Fundamental e devido ao alcance desse programa - para essas coleções foram distribuídos cerca de 80 milhões de exemplares e recursos na ordem de 640 milhões - a pesquisa educacional não pode ignorar a presença desse recurso na vida escolar. Portanto, reafirma-se aqui a relevância e a necessidade de se estudar esses livros didáticos, em contraposição à tendência de se subestimar os livros no âmbito da disciplina de Arte no espaço acadêmico.

Pode-se dizer, de acordo com nossa segunda posição, que os autores das coleções investigadas parecem supor que os professores dominam os fundamentos das quatro linguagens e que são capazes de extrair do tema os conteúdos específicos, ou seja, que levariam a termo a transformação da temática e do conhecimento artístico em formas que sejam pedagogicamente eficazes e possíveis de adaptação nas situações de ensino e aprendizagem. 
Este debate pode ser enriquecido com a compreensão da necessidade de articulação entre os conhecimentos do conteúdo específico e os conhecimentos do campo da Didática, que correspondem aos conhecimentos pedagógicos imprescindíveis aos professores na ação docente. Não se pode perder de vista que o professor de Arte tem diante de si uma tarefa e tanto, pois, ao usar os livros didáticos aqui analisados, tem que buscar soluções aos problemas epistemológicos que dizem respeito à especificidade dos temas e relativas ao domínio das especificidades das abordagens das Artes Audiovisuais e Visuais, da Dança, da Música e do Teatro.

As críticas à História da Arte temática ou por eixos temáticos, que dizem respeito a uma possível pulverização de temas e de conteúdos, articulam-se a outra problemática: supondo-se que o professor não consiga avançar além do presente, nem estabelecer relações, em diferentes temporalidades, entre as funções da arte e da cultura na sociedade, a quem o aluno recorrerá para entender, identificar e explicar as causas e intenções que geram as mudanças na história e na arte? Ora, afirmando nossa terceira posição, é preciso reconhecer que a organização dos conhecimentos históricos por temáticas ou eixos temáticos requer maior protagonismo do professor, o que leva a outra questão crucial: qual é o limite do livro didático frente à formação dos professores para o trabalho com tais propostas?

Para além do que se possa desejar do livro didático, reconhecendo seus limites, problemas e inadequações, o fato é que o livro didático de Arte está presente, em tese, em todas as escolas do país, o que deveria mobilizar o debate sobre a formação nos cursos de licenciatura aos professores de Arte. De forma semelhante, aponta-se a necessidade de um espaço formativo continuado para o estudo e práticas avaliativas sobre o livro didático na rotina escolar de professores. Afinal, se a práxis constitui critério de análise das possíveis saídas para o enfrentamento da fragmentação do conteúdo, não é o professor um protagonista nesse debate? Não é seu interesse pensar como se trabalha com um livro didático?

\section{Referências}

BARBOSA, Ana Mae. A imagem no ensino da arte. São Paulo: Perspectiva, 2002.

SCHLICHTA, Consuelo Duarte; ROMANELLI, Guilherme Ballande; TEUBER, Mauren. 
GARCIA, Tânia M. F. Braga. Os livros didáticos na sala de aula. In: Tânia Maria F. Braga Garcia; Maria Auxiliadora Schmidt; Rafael Valls. (Orgs.). Didática, História e manuais escolares: contextos iberoamericanos. 1. ed. ljuí, RS: Editora Unijuí, 2013, v. 6, p. 69-102

BRASIL. CNE. Resolução no 23, de 23 de outubro de 1973. Fixa normas de estruturação ao curso de Licenciatura em Educação Artística. Livro de Resoluções e Portarias do Conselho Federal de Educação nos anos de 1962 a 1978, Brasília: MEC/CFE, 1979, p.90-93. Disponível em: $<$ http://portal.mec.gov.br/dominio-publico> Acessado em 07/06/2018.

BRASIL, Secretaria de Educação Fundamental. Parâmetros Curriculares Nacionais: História. Secretaria de Educação Fundamental - Brasília: MEC, 1998.

BRASIL. Lei ํㅜ 5692, de 11 de agosto de 1971. Lei de Diretrizes e Bases da Educação Nacional.

BRASIL, Ministério da Educação. PNLD 2017: Arte - Ensino fundamental anos finais. istẹpiBrasília, DF: Ministério da Educação, Secretaria de Educação Básica, 2016.

FONSECA, Selva Guimarães. Didática e prática de ensino de história. São Paulo: Papirus, 2003.

MEIRA, Beá. et al. Projeto Mosaico: Arte. Ensino Fundamental. 1. ed. São Paulo: Scipione, 2015.

PAREYSON, Luigi. Os problemas da estética. São Paulo. Martins Fontes: 1984.

ROSSI, Maria Helena Wagner. A pesquisa no campo da arte-educação visual e o ensino da arte na educação básica. Revista GEARTE, Porto Alegre, v. 1, n. 1, p. 6-100, abr. 2014.

SAVIANI, Dermeval. História das ideias pedagógicas no Brasil. 3. ed. Campinas, SP: Autores Associados, 2010. Coleção memória da educação.

SCHLICHTA, Consuelo A. B. D. e SILVA, Cintia R. V. Formação do professor de arte e políticas públicas: entre o proposto na lei e a realidade, enquanto campos em permanente confronto. In: FONSECA da SILVA, Maria Cristina da R.; SANTOS, Vera Márcia Marques. (Orgs.). Formação docente e políticas públicas: cenários e desafios. Florianópolis: Letras Contemporâneas, 2016, p. 79-98.

UTUARI, Solange et al. Por toda parte. Ensino Fundamental. 1. ed. São Paulo: FTD, 2015.

VAZQUEZ, Adolfo Sanchez. As ideias estéticas de Marx. Trad. Carlos Nelson Coutinho. 2 ed. Rio de Janeiro, Paz e Terra, 1978.

VAZQUEZ, Adolfo Sanchez. Filosofia da práxis. Trad. Luiz Fernando Cardoso. 2. ed. Rio de Janeiro: Paz e Terra, 1977.

WOLFF, Janet. A produção social da arte. Trad. Waltensir Dutra. Rio de Janeiro: Editora Zahar, 1982. 


\section{Consuelo Alcioni Borba Duarte Schlichta}

Pós-Doutorado na UDESC, SC, realizando pesquisa sobe a formação enquanto uma dimensão inseparável da atuação do professor de Artes Visuais, sobretudo as assimetrias entre as propostas curriculares à construção de um novo perfil de professor e de ensino de artes visuais articulados às exigências da contemporaneidade. Doutora em História pela Universidade Federal do Paraná (2006), com pesquisa em história das representações, leitura da imagem e fundamentos teórico-metodológicos do ensino da arte. Mestre em Educação (1998). Professora da UFPR, artivista, ilustradora e autora de livros para educadores em Artes Visuais, Educação Básica e Ensino Médio.

E-mail: consuelo.ufpr@gmail.com

Link Lattes: http://lattes.cnpq.br/7613097165877094

\section{Guilherme Gabriel Ballande Romanelli}

Professor, violinista e violista, possui graduação em Educação Artística - Habilitação em música pela Faculdade de Artes do Paraná (1997) doutorado (2009) e mestrado em Educação (2000) pela Universidade Federal do Paraná. Atualmente é professor da Universidade Federal do Paraná no Departamento de Teoria e Prática de Ensino, do Setor de Educação e do Programa de Pós-Graduação em Música da UFPR. Tem experiência na área de Educação, com ênfase em Educação Musical, atuando nos temas: educação musical, musicalização, formação de professores, manuais escolares, valorização da música popular e construção de instrumentos. Na área musical tem experiência em orquestras sinfônicas, recitais e gravações de CD.

E-mail: guilhermeromanelli@ufpr.br

Link Lattes: http://lattes.cnpq.br/7121843222449377

\section{Mauren Teuber}

Doutorado (2016) e Mestrado em Educação (2007) pela Universidade Federal do Paraná. Realizou estágio de doutoramento na Florida State University, programa CAPES/ FULBRIGHT (2015). Bacharelado no Curso Superior de Pintura pela EMBAP/PR (2000) e especialização em Ensino de Artes Visuais pela UDESC (2003). Professora do Curso de Licenciatura em Artes Visuais, da Universidade Estadual do Paraná, Campus de Curitiba II. Integrante do Grupo de Pesquisa Arte, Ensino e Formação Continuada, UNESPAR e do Núcleo de Pesquisa em Publicações Didáticas, UFPR. Desenvolve pesquisas na área de formação de professores, com enfoque nas relações entre artistaprofessor-pesquisador e sobre materiais didáticos para Artes Visuais.

E-mail: maurenteuber@gmail.com

Link Lattes: http://lattes.cnpq.br/8866895398999616

Recebido em 15 de junho de2018

Aceito em 15 de agosto de 2018

SCHLICHTA, Consuelo Duarte; ROMANELLI, Guilherme Ballande; TEUBER, Mauren.

Livros didáticos para o ensino da arte: não peça a eles o que eles não podem te dar.

Revista GEARTE, Porto Alegre, v. 5, n. 2, p. 312-325, maio/ago. 2018.

Disponível em: http://seer.ufrgs.br/gearte 